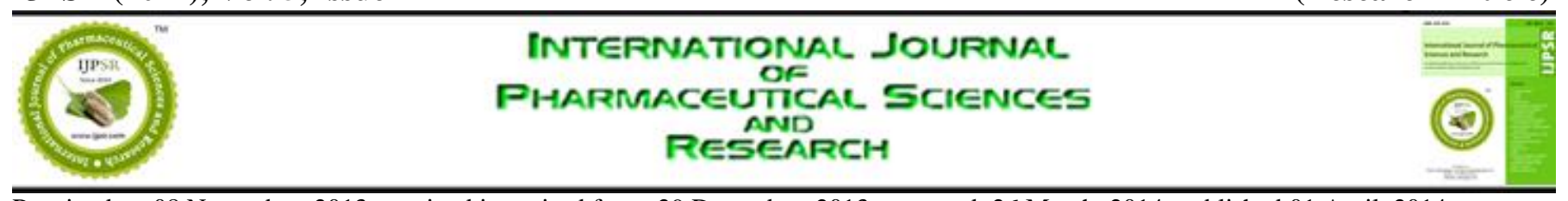

Received on 08 November, 2013; received in revised form, 29 December, 2013; accepted, 26 March, 2014; published 01 April, 2014

\title{
KNOWLEDGE ON MEDICATION TAKING BEHAVIOUR, BALANCED DIET AND PHYSICAL ACTIVITY - A SURVEY AMONG THE ADOLESCENTS
}

Mounika $\mathrm{S}^{* 1}$, Raghuram $\mathrm{V}^{2}$, Chaitanya Lakshmi $\mathrm{CH}^{2}$, Rama Rao $\mathrm{N}^{3}$

Pharm D, Department of Pharmacy Practice, Chalapathi Institute of Pharmaceutical Sciences, Acharya Nagarjuna University, Guntur, Andhra Pradesh, India

Keywords:

Medication taking behaviour, Dietary habits, Physical activity, Questionnaire

Correspondence to Author:

Mounika Somepalli

Pharm D, Department of Pharmacy

Practice, Chalapathi Institute of

Pharmaceutical Sciences, Acharya

Nagarjuna University, Guntur,

Andhra Pradesh, India

Email: mounika.somepalli@gmail.com

\begin{abstract}
The main objective of the study is to promote awareness and assess the knowledge of adolescents on medication use, importance of balanced diet and physical activity. The study was conducted among the adolescents' aged from16-18 years in regions of Guntur. The volunteers are allowed to fill their informed consent to be a part of the study. The questionnaire was distributed to all the volunteers included in the study, which includes questions on their medication taking behaviour, dietary habits and physical activity. The response was then analysed to assess the knowledge on medication use, balanced diet and physical activity. Among the 165 individuals on assessment of their medication taking behaviour $78 \%$ of them do not follow their prescription, $61 \%$ of the individuals do not have any idea on their medication use and a majority of $74 \%$ are not aware of the unwanted effects caused by the medication. On assessment of their dietary habits and physical activity, $62 \%$ of the individuals include meal rich in fat, $42 \%$ of the individuals skip their breakfast every day and $41 \%$ of them will not include leafy vegetables as part of their regular meal. $65 \%$ of individuals do not perform a regular physical activity. It is the responsibility of the pharmacist to promote awareness on the medications, balanced diet and physical activity to improve the quality of life of an individual.
\end{abstract}

INTRODUCTION: Appropriate medicine use and dietary habits helps an individual lead a healthy life. Irrational use of medicine is a major problem everywhere. Identifying conditions that coexist with illicit drug use is necessary for planning health services. This made us to select medication taking behaviour of the community.

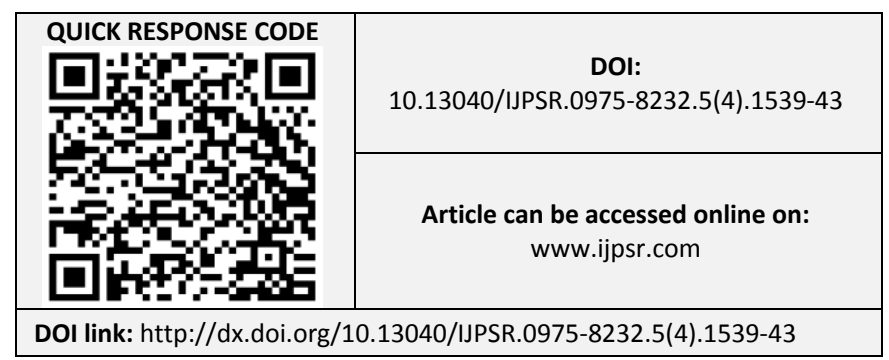

In day to days life style most of the people are leading a sedentary life without any physical activity and are mostly attracted to junk foods which are leading to many health issues. So we have also focused on the dietary habits and physical activity of the people. WHO estimates that more than half of all medicines are prescribed, dispensed or sold inappropriately, and that half of all patients fail to take them correctly, also irrational use of drugs may lead to poly-pharmacy, antibiotic resistance, and non-adherence to medication ${ }^{1}$. The scientific evidence available for the age group 5-17 years supports that physical activity provides fundamental health benefits for children and adolescents $^{2}$. 
Moreover, physical activity has been associated with psychological benefits in young people by improving their control over symptoms of anxiety and depression; and assisting in social development ${ }^{3,4,5}$. The main objective of the study is to assess the knowledge of adolescents on medication taking behaviour, dietary habits and physical activity and also to promote awareness on those issues which helps them understand the importance of each and supports them to lead a better quality living $6,7,8,9$.

Now days, many people irrespective of their age are prone to diseases, which reduce their Quality of Life. Many studies have confirmed that our living conditions may reflect the health status, and also our disease state. As a member of Health care team, it is our duty to assess the medication taking behaviour especially on Out-Patient settings, and also to provide information regarding appropriate medicine use and the importance of proper diet and regular exercise ${ }^{10,11,12,13,14}$.

Initially, to assess on medication taking behaviour, we have selected rural areas, where medication abuse promotes primarily, because majority of them are illiterates. People in rural areas do not balance their daily food intake with their physical activity. This may also leads to the opening gates to disease pattern. To assess all these parameters, we have selected regions in Guntur district for a period of 3 months. As part of our protocol, we have prepared a questionnaire to assess each parameter of our objective in English and also in local language for their easy accessibility.

MATERIALS AND METHODS: Overall 165 participants of age group between 16-18 years were included in the study. Age wise and gender wise distribution of the volunteers are given in Figures 1 and 2 respectively. Initially, as per our basic requirement, informed consents from all the volunteers have been attained. All the participants willing to fill their consent were included and those who do not meet the criteria have been excluded from the study. Male and female participants are categorized randomly into two groups. Each participant is made to sign their informed consent, and the questionnaires were distributed to all the participants who were involved in the study. They are allowed to fill the questionnaire which focuses on their medication use, dietary habits and physical activity. Once the process was completed, participants are allowed to submit their questionnaire along with signed consent. After collecting the forms, our representatives have conducted an awareness program and distributed information brochure on matters related to importance of appropriate medicine use, balanced diet and physical activity. The response was then evaluated by using statistical analysis and the results were interpreted.

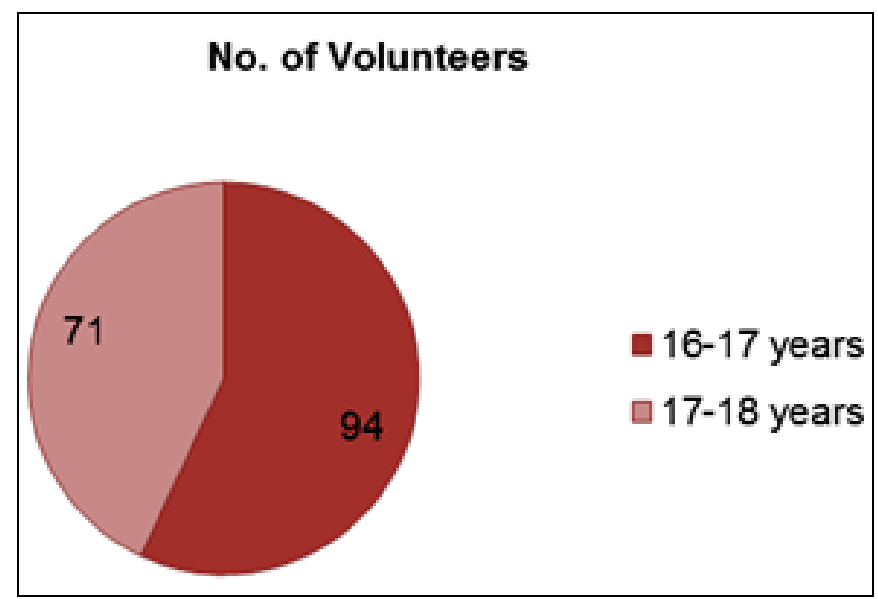

FIGURE 1: AGE WISE DISTRIBUTION OF THE VOLUNTEERS

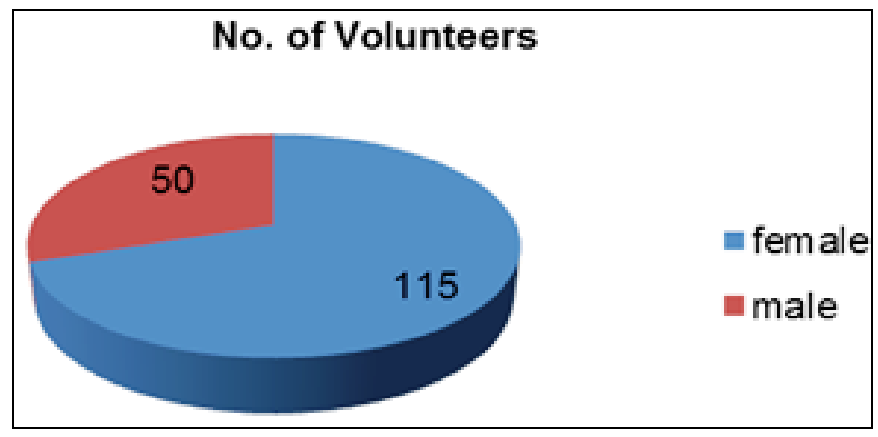

FIGURE 2: GENDER WISE DISTRIBUTION OF THE VOLUNTEERS

RESULTS: Among 165 participants when assessed on the medication taking behaviour of the individuals, it was found that only $17 \%$ (29) of the people regularly follow their prescription, and $78 \%$ (129) of them do not follow their prescription, which is a major concern to the health care professionals. Timely use of medication may help in proper prognosis of the condition, when misused, it may worsen the condition. Here, $25 \%$ (42) of the individuals were aware of their medication use, whereas $61 \%$ (102) do not have any idea on their medication use. Health care professionals play a major role in educating the people about unwanted effects of medicine which promotes medication adherence. In our study, it 
was found that, majorly $74 \%$ (122) of the people were not aware of the unwanted effects caused by the medication, where only $26 \%$ (43) were aware of its unwanted effects. Further information on medication taking behaviour among the volunteers is given in Figure 3.

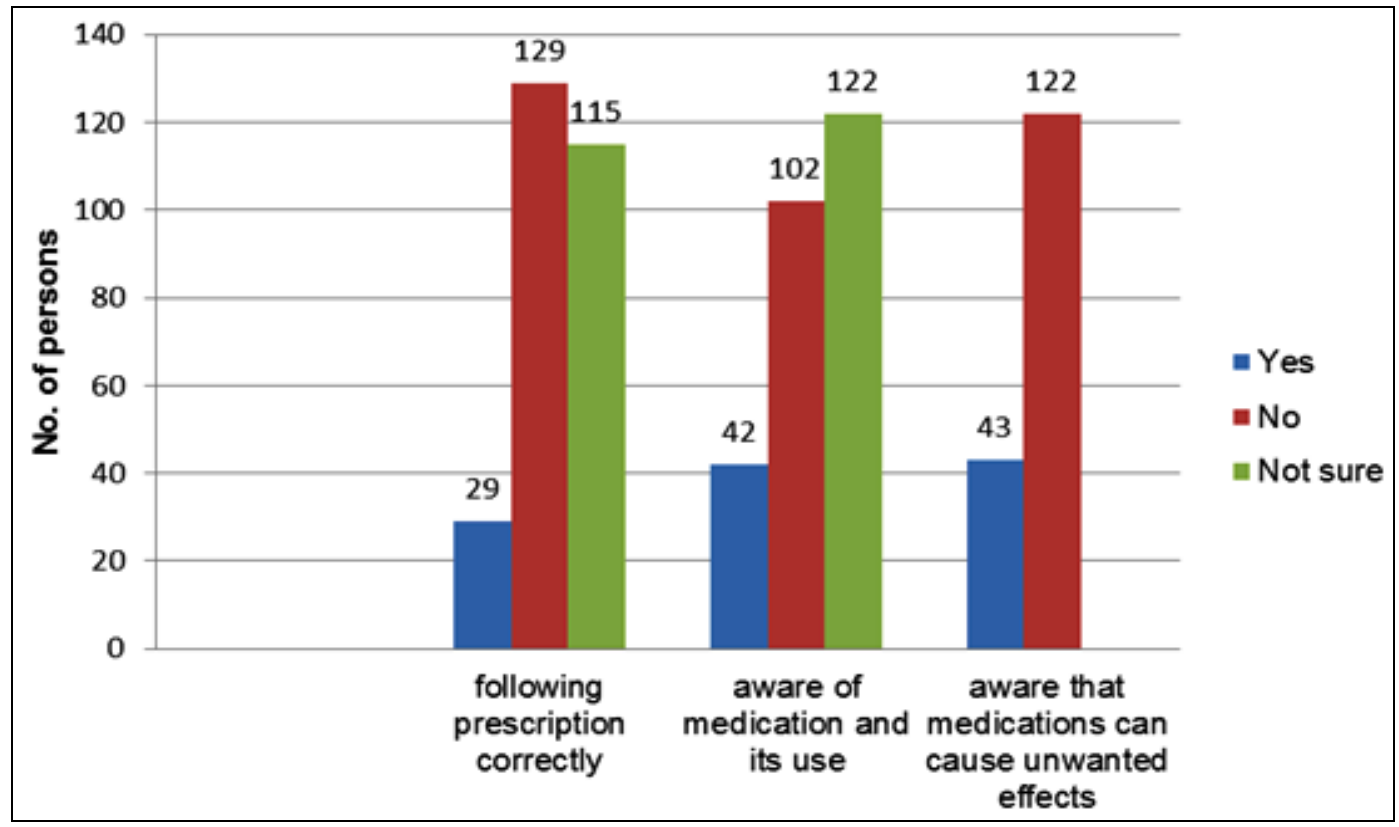

FIGURE 3: MEDICATION TAKING BEHAVIOUR OF THE VOLUNTEERS

Good nutrition, regular physical activity, and maintaining a healthy body weight are cornerstones of health at every stage of life. On the other hand, when assessed on their regular diet and physical activity $65 \%$ (108) of individuals do not perform their physical activity.

Further details on physical activity of the volunteers are furnished in Figure 4. But according to WHO Guidelines; on an average 60 minutes of physical activity is required every day ${ }^{2}$.

By having regular breakfast and including green leafy vegetables and fruits as part of the meals which consists of vitamins, minerals and antioxidants will help lead a healthy life, here $42 \%$ (70) of the individuals skip their breakfast every day.

Further details on comparative questions related to breakfast habits of volunteers are given in Figure 5. $41 \%$ (68) of them will not include leafy vegetables as part of their regular meal. Further details on comparative questions regarding the inclusion of green leafy vegetables are furnished in Figure 6. $62 \%$ (102) of the individuals include meal rich in fat. A further detail on the type of food taken by the individuals is given in Figure 7.

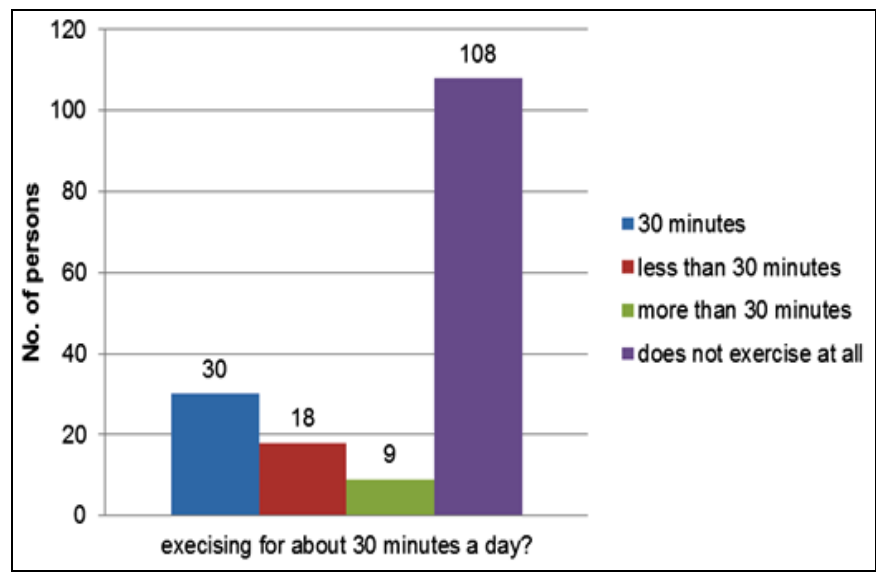

FIGURE 4: PHYSICAL ACTIVITY OF VOLUNTEERS

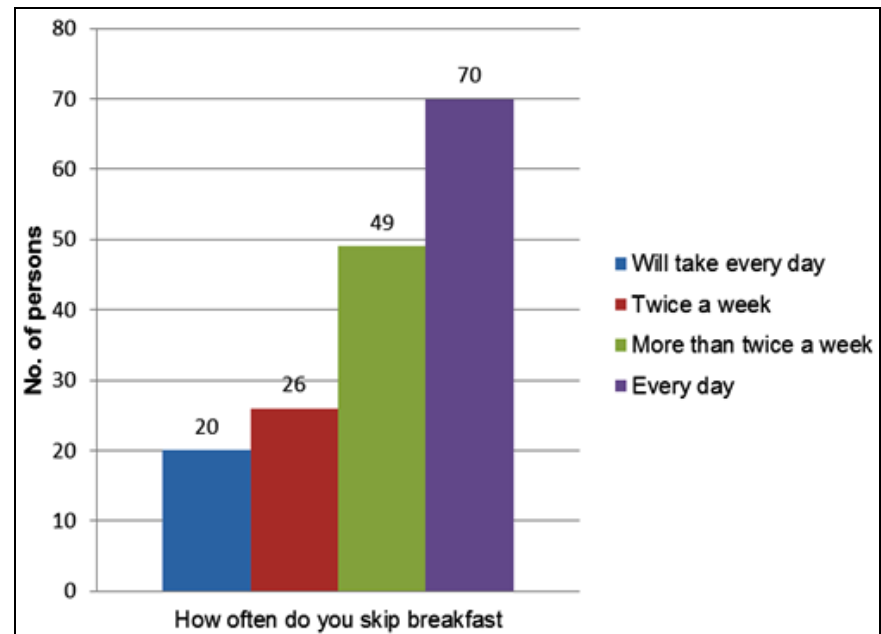

FIGURE 5: BREAKFAST HABITS OF THE VOLUNTEERS 


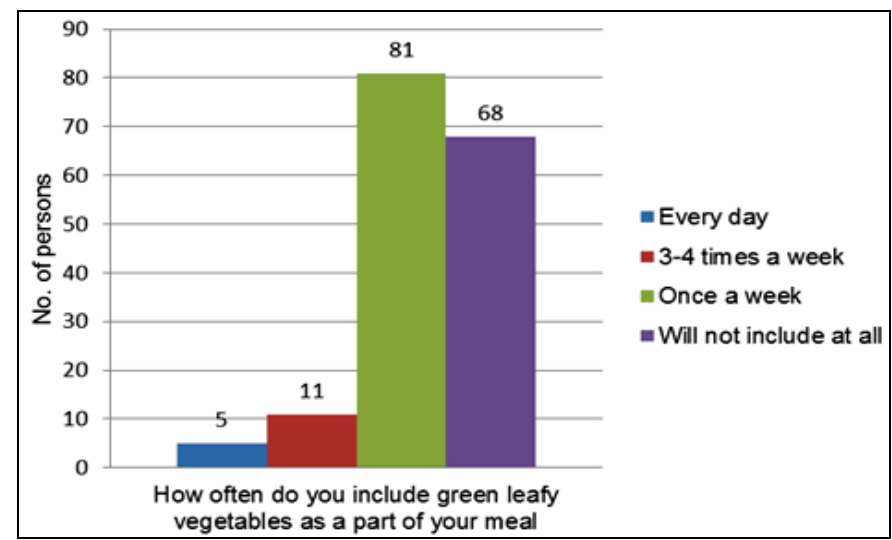

FIGURE 6: COMPARISON BETWEEN FREQUENCIES OF INCLUDING GREEN LEAFY VEGETABLES AS PART OF THEIR MEAL AMONG THE VOLUNTEERS

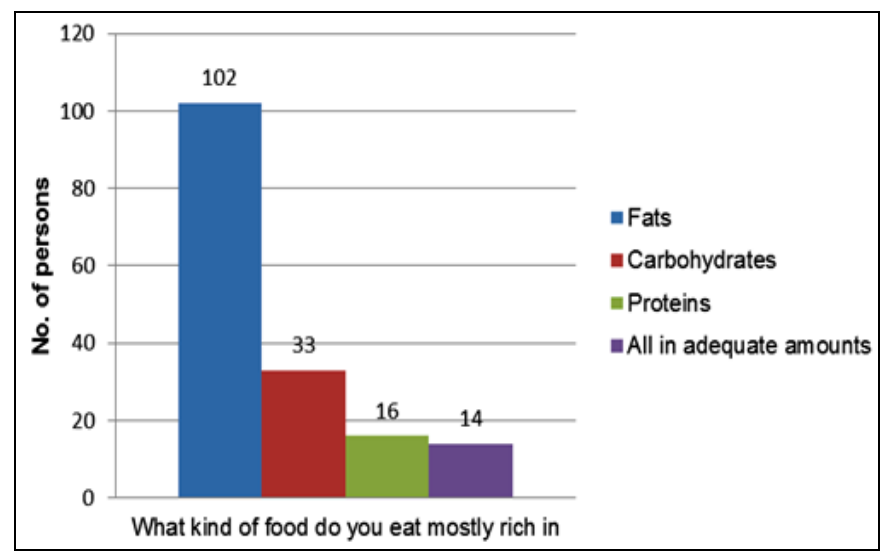

FIGURE 7: TYPE OF FOOD TAKEN BY THE VOLUNTEERS

DISCUSSION: Medication, when used appropriately as per the physician's order it may relieve the symptoms, but when misused it may worsen the condition $11,13,15,17$. Here only $17 \%$ of the people regularly follow their physician's order when necessary. Majority of them do not follow, which is threatening to health. Basic knowledge is required about the drug which we take regularly. So that, it may help us avoid abuse of that drug, and alarm us on its unwanted effects. But in our study, we found only $25 \%$ of the individuals are aware of their medications and its uses. Most of them do not know that medication may cause severe effects when it was abused. These factors promote the use of OTC medications, thereby resulting in irrational medicine use.

In a study, the authors identified the common problems of medicine use by using a crosssectional, pilot-tested questionnaire in order to improve the appropriate use of medicines on exit from primary health care centres. The authors checked whether the medicines are being used properly, from the time of dispensing till their administration. It was found that, $51 \%$ failed to go for follow-up to the same facility. A total of $70 \%$ stopped taking their medicines when symptoms disappeared; $26 \%$ were unaware that most medicines have side-effects and $61 \%$ did not realise that injections are the riskiest dosage form. As it is a major concern that majority of the medicines are being misused. Many of these results can be improved by a well-targeted public education campaign ${ }^{16}$.

Thus, the duty lies on all the health care professionals to educate the people on timely use of medicines. They should tell patient to improve their medication taking behavior which helps them improve quality of living. Many patients do not recollect the information, which was provided by their physician or pharmacist, so at this point, Information Brochures or Leaflets helps them follow as their guidance.

Balanced Diet, physical activity and hygienic living conditions help us maintain healthy body weight. In our study, majority of people include meal rich in fat and do not perform any physical activity. This leads to the increase in body weight, and more prone to the chronic conditions.

In another study, which comprised of total 2176 adolescents (46.2\% male) from ten European Cities participating in the HELENA (Healthy Lifestyle in Europe by Nutrition in Adolescence) study, dietary intake and physical activity were assessed using validated 24-h dietary recalls and self-reported questionnaires respectively. In both sexes, the authors found no differences in energy intake and between the levels of physical activity.

The most active males showed a higher intake of polysaccharides, protein, water and vitamin $\mathrm{C}$ and a lower intake of saccharides compared to less active males. Females with the highest physical activity level consumed more polysaccharides compared to their least active peers. The consumption of foods from the remaining food groups did not differ between the physical activity levels in both sexes. Finally, they have concluded that dietary habits diverge between adolescents with different selfreported physical activity levels. They have also concluded that physically active adolescents are not always inclined to eat healthier diets than their less active peers ${ }^{6}$. 
Thus, inclusion of diet which consists of all essential nutrients and balancing physical activity helps our body maintain normal body weight. Many studies suggest that adolescent age group neglects these factors to the extent, which makes them prone to many deficiency disorders. So, preventive measures have to be taken to avoid these factors, which maintain their Mean Body Weight.

CONCLUSION: Inappropriate use of medicine and intake of unbalanced diet, without any physical activity is widely promoting in day-to-day life of the adolescents which has a major impact on their quality of life. Children and adolescents who take a healthy diet with physical activity are more likely to reach and maintain a healthy weight, achieve normal growth and development, and have strong immune systems. Therefore it is the responsibility of the pharmacist to promote awareness on these issues to improve the quality of life of an individual.

ACKNOWLEDGEMENT: We thank all the volunteers who had actively participated in the survey. We extend our gratitude to all our faculty and students of Chalapathi Institute of Pharmaceutical Sciences for providing us facilities and helped us in completing the survey..

\section{REFERENCES:}

1. Ahmed Abdo-Rabbo, Manal Al-Ansari, Brian C Gunn,* and Batool J Suleiman; The Use of Medicines in Oman-Public Knowledge, Attitudes and Practices; Sultan Qaboos Univ Med J. 2009 August; 9(2): 124-131.

2. Alipta Dutta and Subrata Chakraborty; Practice of rational drug uses in a rural area of $24 \mathrm{pgs}(\mathrm{s})$ in West Bengal; J Adv Pharm Technol Res. 2010 Jul-Sep; 1(3): 358-364. doi: 10.4103/01105558.72421

3. Apolinaras Zaborskis, 1 Reda Lagunaite,1 Ryan Busha,1 and Jolita Lubiene; Trend in eating habits among Lithuanian schoolaged children in context of social inequality: three cross-sectional surveys 2002, 2006 and 2010; BMC Public Health. 2012; 12: 52.

4. Ashley Wilder Smith, Laurel A. Borowski, Benmei Liu, et.al, U.S. Primary Care Physicians' Diet, Physical Activity, and Weight-Related Care of Adult Patients; Am J Prev Med. Author manuscript; available in PMC 2012 July 1.
5. Carl Lachat, Stephen Otchere, Dominique Roberfroid; Diet and Physical Activity for the Prevention of Noncommunicable Diseases in Low- and Middle-Income Countries: A Systematic Policy Review; PLoS Med. 2013 June; 10(6): e1001465.

6. Charlene Ottevaere, Et.al, Relationship between self-reported dietary intake and physical activity levels among adolescents: The HELENA study; Int J Behav Nutr Phys Act. 2011; 8: 8.

7. Gisela Nyberg, 1 Elinor Sundblom, Åsa Norman, and Liselotte Schäfer Elinder; A healthy school start - Parental support to promote healthy dietary habits and physical activity in children: Design and evaluation of a cluster-randomised intervention; BMC Public Health. 2011; 11: 185.

8. Ifeoma N Onyeka 1, Caryl M Beynon,2 Hanna Uosukainen,3 et.al., Coexisting social conditions and health problems among clients seeking treatment for illicit drug use in Finland: The HUUTI study; BMC Public Health. 2013; 13: 380.

9. Ikuko Aoyama 1 Shinichi Koyama,1 and Haruo Hibino; Selfmedication behaviors among Japanese consumers: sex, age, and SES differences and caregivers' attitudes toward their children's health management; Asia Pac Fam Med. 2012; 11(1): 7.

10. Kathryn M. Orzech, James Vivian, Cristina Huebner Torres; Diet and Exercise Adherence and Practices Among Medically Underserved Patients With Chronic Disease: Variation Across Four Ethnic Groups; Health Educ Behav. Author manuscript; available in PMC 2013 June 3.

11. Marko T. Kantomaa, Emmanuel Stamatakis, Anna Kankaanpää, et.al,; Physical activity and obesity mediate the association between childhood motor function and adolescents' academic achievement; Proc Natl Acad Sci U S A. 2013 January 29; 110(5): 1917-1922.

12. Sweis D, Wong IC. Giving medicines to children: understanding the parents' views. Paediatric Drugs.2004;6:67-9. [PubMed]

13. Tjeerd Van der Veer, Monique H. W. Frings-Dresen, and Judith K. Sluiter*; Health Behaviors, Care Needs and Attitudes towards Self-Prescription: A Cross-Sectional Survey among Dutch Medical Students; PLoS One. 2011; 6(11): e28038.

14. T L Mukattash, J S Millership, P S Collier, and J C McElnay; Public awareness and views on unlicensed use of medicines in children; Br J ClinPharmacol. 2008 December; 66(6): 838-845.

15. Umar M Lawan, Isa S Abubakar, Abubakar M Jibo, Ahmed Rufai ; Pattern, Awareness and Perceptions of Health Hazards Associated with Self Medication Among Adult Residents of Kano Metropolis, Northwestern Nigeria; Indian J Community Med. 2013 Jul-Sep; 38(3): 144-151.

16. Wei Bao, Aiguo Ma, Limei Mao et.al; Diet and lifestyle interventions in postpartum women in China: study design and rationale of a multicenter randomized controlled trial; BMC Public Health. 2010; 10: 103. Published online 2010 February 27. doi: $10.1186 / 1471-2458-10-103$.

17. Global Recommendations on Physical Activity for Health; A WHO Group Report. Available from: http://www.who.int/ dietphysicalactivity/physical-activity-recommendations-517years.pdf

18. Royal College of Paediatrics. Medicines for Children. London: RCPCH; 1999.

19. World Health Organisation media centre. Promoting rational use of medicines saves lives and money, WHO experts say. Available from: http://www.who.int/mediacentre/news/notes /2004/np9 /en/[PubMed].

\section{How to cite this article:}

Mounika S*1, Raghuram V 2, Chaitanya Lakshmi CH 2, Rama Rao N: Knowledge on medication taking behaviour, balanced diet and physical activity - A survey among the Adolescents. Int J Pharm Sci Res 2014; 5(4): 1539-43.doi: 10.13040/IJPSR.0975-8232.5(4).1539-43

All @ 2013 are reserved by International Journal of Pharmaceutical Sciences and Research. This Journal licensed under a Creative Commons Attribution-NonCommercial-ShareAlike 3.0 Unported License.

This article can be downloaded to ANDROID OS based mobile. Scan QR Code using Code/Bar Scanner from your mobile. (Scanners are available on Google Playstore) 